\title{
The pathophysiology and treatment of delayed cerebral ischaemia following subarachnoid haemorrhage
}

\author{
Karol P Budohoski, ${ }^{1}$ Mathew Guilfoyle, ${ }^{1}$ Adel Helmy, ${ }^{1}$ Terhi Huuskonen, ${ }^{1,2}$ \\ Marek Czosnyka, ${ }^{1}$ Ramez Kirollos, ${ }^{1}$ David K Menon, ${ }^{3}$ John D Pickard, ${ }^{1}$ \\ Peter J Kirkpatrick'
}

\begin{abstract}
- Additional material is published online only. To view please visit the journal online (http://dx.doi.org/10.1136/ jnnp-2014-307711).

${ }^{1}$ Division of Neurosurgery, Department of Clinical Neurosciences, Addenbrooke's Hospital, University of Cambridge, Cambridge, UK ${ }^{2}$ Department of Neurosurgery, Kuopio Neurocenter, Kuopio University Hospital, Kuopio, Finland

${ }^{3}$ Department of Anaesthesiology, Addenbrooke's Hospital, University of Cambridge, Cambridge, UK
\end{abstract}

Correspondence to Dr Karol P Budohoski, Division of Neurosurgery, Addenbrooke's Hospital, Hills Road, Box 167, Cambridge CB2 OQQ, UK; karol.budohoski@gmail.com

Received 24 January 2014 Revised 1 April 2014 Accepted 8 April 2014 Published Online First 20 May 2014
CrossMark

\begin{tabular}{l}
\hline To cite: Budohoski KP, \\
Guilfoyle M, Helmy A, et al. \\
J Neurol Neurosurg \\
Psychiatry 2014;85: \\
1343-1353. \\
\hline
\end{tabular}

\section{ABSTRACT}

Cerebral vasospasm has traditionally been regarded as an important cause of delayed cerebral ischaemia (DCI) which occurs after aneurysmal subarachnoid

haemorrhage, and often leads to cerebral infarction and poor neurological outcome. However, data from recent studies argue against a pure focus on vasospasm as the cause of delayed ischaemic complications. Findings that marked reduction in the incidence of vasospasm does not translate to a reduction in $\mathrm{DCl}$, or better outcomes has intensified research into other possible mechanisms which may promote ischaemic complications. Early brain injury and cell death, blood-brain barrier disruption and initiation of an inflammatory cascade, microvascular spasm, microthrombosis, cortical spreading depolarisations and failure of cerebral autoregulation, have all been implicated in the pathophysiology of $\mathrm{DCl}$. This review summarises the current knowledge about the mechanisms underlying the development of DCl. Furthermore, it aims to describe and categorise the known pharmacological treatment options with respect to the presumed mechanism of action and its role in $\mathrm{DCl}$.

\section{INTRODUCTION}

The incidence of spontaneous subarachnoid haemorrhage (SAH) is around 6-11 per 100000 persons per year. ${ }^{12}$ Due to the relatively young age of the affected population and the high rates of disability, the burden to society is high, with a reported loss of productive years similar to ischaemic and haemorrhagic strokes. ${ }^{3}$

Over the past two decades, the advancement of understanding of the pathophysiology of SAH and its squelae has led to a considerable reduction in the mortality. ${ }^{4}$ Data suggest that this reduction may be related to new management protocols directed at early aneurysm repair, and aggressive management of acute hydrocephalus and delayed cerebral ischaemia (DCI). ${ }^{4}$ Despite these advances, about $30 \%$ of patients who survive following SAH will not regain full independence, ${ }^{6}$ while $69 \%$ will report a reduced quality of life. ${ }^{7}$

DCI is recognised as one of the leading causes of unfavourble outcome following SAH. ${ }^{8}$ Understanding the exact mechanisms which lead to DCI is important in the development of new treatment strategies. Furthermore, with multiple therapies being tested, it is important to understand the background behind the interventions, as well as the current state of evidence for their likely benefit.

\section{$\mathrm{DCI}$}

DCI has been shown to occur in $30-40 \%$ of patients with SAH. ${ }^{8}{ }^{9-11}$ The pathophysiology of DCI is complex and not fully understood. Until recently, the prevailing view has been held that there is a direct link between arterial narrowing seen on angiography and clinical symptoms of brain ischaemia. However, recent data argue that this relationship is inconsistent. While angiography and perfusion imaging often demonstrate vasospasm and associated perfusion deficits, this is by no means invariable, and in many cases, DCI may be a diagnosis of exclusion without clear radiological findings.

\section{CEREBRAL VASOSPASM}

Ecker and Riemenschneider ${ }^{12}$ first documented the presence of cerebral vasospasm (CVS) in relation to a ruptured aneurysm. Allcock and Drake ${ }^{13}$ demonstrated a link between vasospasm and symptoms of focal ischaemia. Arterial narrowing has typically been shown to have a delayed onset and a peak between 5 and 14 days, following which it typically resolves (figure 1). ${ }^{14}$ It is, therefore, understandable as to why CVS has been related to delayed deterioration. ${ }^{14-18}$

Multiple signalling pathways have been implicated in the pathogenesis of arterial spasm. The principal initiating factors are thought to be blood degradation products which accumulate in the subarachnoid space and act as triggering substances for the development of endothelial dysfunction and an intramural inflammatory response.

\section{Blood degradation products}

Clinically, there is a clear link between the severity of CVS and the amount of subarachnoid blood seen on $\mathrm{CT}^{19-23}$ a relationship recognised by the Fisher scale. ${ }^{19}$ The contractile property of cerebrospinal fluid (CSF) from patients with SAH was first described by Buckell. ${ }^{24}$ Since then it has been demonstrated that blood degradation products trigger a molecular cascade which leads to CVS. Several key observations support the role of oxyhaemoglobin, in particular, in the pathogenesis of post-SAH 
Figure 1 Flow velocity changes in a cohort of subarachnoid haemorrhage patients. An increase of FV can be seen from day 6 with a peak at day 10-12. Spontaneous resolution not clearly seen as patient numbers decreased in the second and third week due to discharge. Horizontal dashed line represents FV threshold of $120 \mathrm{~cm} / \mathrm{s}$, typically used in the diagnosis of cerebral vasospasm (CVS). Vertical dashed line is the median time of vasospasm onset. FV, flow velocity.

vasospasm. It was shown to induce vasoconstriction in cerebral arteries in vitro. ${ }^{25-27}$ Furthermore, intrathecal injection of oxyhaemoglobin, or a supernatant from autologous blood, was shown to induce vasospasm in primates. Importantly, in the same experiment, injection of methaemoglobin, bilirubin or sham CSF did not induce vasospasm. The exact mechanisms by which oxyhaemoglobin induces vasoconstriction remain unknown, but several key factors have been described. Oxyhaemoglobin is known to alter the synthesis of eicosanoids in vessel walls, in particular, decrease the production of $\mathrm{PGI}_{2}$ and increase the production of $\mathrm{PGE}_{2}$. Furthermore, oxyhaemoglobin spontaneously oxidises to methhaemoglobin releasing superoxide, which in turn, is known to lead to lipid peroxidation and vasoconstriction. Finlay, it has been demonstrated that oxyhaemoglobin inhibits endothelialdependent relaxation. ${ }^{22}$ However, experimental and clinical studies have not, so far, demonstrated that inhibition of any one of these mechanisms alone can completely reverse vasospasm, further confirming a multidirectional effect of blood degradation products on cerebral vasculature. At present the molecular pathways remain largely unknown, and there are no effective pharmacological means to influence all the implicated mechanisms. However, approaches aimed at clearing subarachnoid spaces form blood products seem reasonable.

\section{Inflammation}

Blood-brain barrier breakdown as a consequence of SAH has been shown to lead to trafficking of lymphocytes into the CSF, as well as infiltration of arterial walls. ${ }^{28-31}$ While little direct evidence exists confirming that an induced inflammatory process may directly lead to development of vasospasm, it has been demonstrated that activated mononuclear cells within the CSF can release ET-1, a known vasoconstricting agent. ${ }^{32}$ Furthermore, blood degradation products were shown to be sufficient to induce ET-1 production by activated mononuclear cells providing a direct link between $\mathrm{SAH}$, inflammation and ET-1 production. ${ }^{32}$ Longitudinal analysis of the inflammatory reaction after SAH revealed that there is a massive, compartmentalized increase in the secretion of proinflammatory cytokines such as IL-1 $\beta$ and IL- $6 .^{33}$ Furthermore, the changes in cytokine concentrations parallel the changes in blood flow velocity. $^{33}$

Nitric oxide and nitric oxide synthase

Nitric oxide (NO) is one of the key endothelium-derived factors which govern vascular muscle tension. It increases $3^{\prime}, 5^{\prime}$-cyclic guanosine monophosphate (cGMP) levels in vascular smooth muscle cells leading to vasodilatation and an increase in cerebral blood flow. ${ }^{34} 35$ NO levels are known to decrease following SAH in a characteristic biphasic distribution: acute-30 min after the ictus $^{36}$; and delayed-around 4-7 days following the ictus. ${ }^{37} 38$ Whether, this is a result of binding by oxyhaemoglobin or secondary to an inflammatory process remains unknown. Furthermore, while shear stress induces vasodilatation in healthy arteries via endothelial NO synthase (NOS), this pathway is impaired following $\mathrm{SAH}^{39}{ }^{40}$ with a clear reduction in NOS mRNA reported on day 7 post-ictus. ${ }^{41}$ Furthermore, endogenous inhibitors of endothelial NOS, such as asymmetric dimethylargnine and protein kinase $\mathrm{C}$ have been described to be upregulated following SAH. ${ }^{42-44}$ Experimental and human data suggest that vasospasm can be ameliorated with the aid of exogenous NO donors such as sodium nitroprusside or nitroglycerine. ${ }^{45}{ }^{46}$ However, adverse systemic effects of these medications (principally hypotension, which has been shown to be more pronounced than that seen with nimodipine) make them inappropriate for routine systemic administration in clinical practice. Nevertheless, it needs to be pointed that a number of studies have investigated intrathecal administration of $\mathrm{NO}$ donors in humans with little systemic side effects. However, the deactivation of NO exposed to oxyhaemoglobin and deoxyhaemoglobin, (formation of methaemoglobin, S-nitroso-haemoglobin and ferrous-nitrosyl-haemoglobin) remains a concern (see Pluta ${ }^{47}$ for a detailed review on NO and DCI). Recently the safety of systemic administration of sodium nitrate in humans has been confirmed, with potential clinical trials in SAH awaited. ${ }^{48}$

\section{Endothelin-1}

Endothelin-1 (ET-1), one of the most potent endogenous vasoconstrictors, produced by endothelial cells, is stimulated by ischaemic insult, but also by oxyhaemoglobin. ${ }^{49}$ The levels of ET-1 in the CSF of patients with vasospasm have been shown to be higher than those found in healthy subjects. ${ }^{50} \quad 51$ Furthermore, increases in ET-1 levels correlate with the onset of ischaemic symptoms. ${ }^{50} 51$ However, other studies demonstrated that, although, ET-1 levels were higher in patients with DCI, they were within normal range in patients with angiographic evidence of arterial narrowing without clinical symptoms, ${ }^{52}$ suggesting that ET-1 may be a marker of ischaemic tissue damage rather than vasospasm. ${ }^{52}$ While the exact role of ET-1 in the development of CVS is unknown, it has been demonstrated that administration of ET-1 receptor type A (ETA) antagonists in an experimental setting reduced vasospasm. ${ }^{53} 54$ Similar findings were reported in the randomised controlled trial of Clazosentan (an ETA receptor antagonist), where inhibition of ET-1 signalling significantly reduced large vessel narrowing in a clinical setting. ${ }^{55-59}$

\section{THE RELATIONSHIP BETWEEN VASOSPASM AND DCI}

Narrowing of cerebral arteries may cause a reduction of cerebral blood flow distal to the spastic segment, depending on the state of autoregulation, which in consequence, may lead to ischaemia and infarction. ${ }^{60-63}$ However, while up to $70 \%$ of patients demonstrate a degree of arterial narrowing on catheter angiography, ${ }^{64} 65$ 
only $20-30 \%$ develop clinical symptoms. ${ }^{66}$ The positive predictive value of vasospasm (diagnosed using stringent criteria with the aid of two imaging methods) for DCI is only $67 \% .^{8}$ Furthermore, up to $25 \%$ of delayed infarcts seen on follow-up CT are not located in the territory of the spastic artery, or are found in patients who did not demonstrate vasospasm. ${ }^{67-69}$

A number of studies suggested that only severe vasospasm with at least $50 \%$ luminal narrowing produces a reduction of cerebral blood flow which is sufficient to cause symptoms of ischaemia. ${ }^{17} 63{ }^{70-74}$ However, others have reported that only $50 \%$ of patients with severe CVS on angiography become symptomatic. $^{60}$ Positron emission tomography (PET) has shown that delayed neurological deficits after SAH were associated with a wide range of haemodynamic disturbances, ranging from hypoperfusion to hyperaemia, ${ }^{75}$ and that the spatial distribution of the haemodynamic disturbances did not always coincide with the vascular territory where narrowing was identified. ${ }^{70} 7576$ With a more widespread use of perfusion imaging methods (such as perfusion CT) for the evaluation of DCI, similar findings are being increasingly reported (figure 2). ${ }^{77}$

By contrast, some studies, with rigorous angiographic control, report that indeed, there is a significant correlation between angiographic vasospasm, DCI and delayed infarctions on follow-up imaging, and that only $3 \%$ of patients with none or only mild angiographic spasm develop delayed infarcts. ${ }^{16}$ These findings spark the question, whether other factors may responsible for the observed discrepancies. It is known that transcranial Doppler (TCD) diagnosis of vasospasm is limited mainly to the anterior circulation and, in particular, to the middle cerebral artery, therefore, spasm in other vessels may be misinterpreted. Furthermore, infarction on follow-up imaging needs to be interpreted with caution in the absence of immediate postoperative imaging to rule out other, potentially iatrogenic causes. As immediate postoperative imaging is not standard practice in many centres, this is not always reported. While in most cases, $\mathrm{SAH}$ is promptly diagnosed and the culprit aneurysm detected and treated, there remains a population of patients with a delayed presentation with only minimal symptoms who may have been exposed to haemodynamic instability in the early phase post-bleed.
Nevertheless, a recent meta-analysis of pharmacological treatment of vasospasm and DCI demonstrated that, despite a reduction in the incidence of CVS, there was, in most cases, little or no effect on outcome. ${ }^{78}$ Similar results were reported from the trial of clazosentan (a potent ETA receptor antagonist) as well as nicardipine (potent calcium channel blocker). ${ }^{55} 79$ Conversely, nimodipine, which is so far, the only drug for which class I evidence exists, reduced the incidence of DCI and poor outcome by $40 \%$, without ameliorating vasospasm. ${ }^{80-82}$

While many of the disappointing results may have been a consequence of systemic complications of the investigated compounds, which often caused blood pressure instability or pulmonary complications (such as those observed in trials of clazosentan and nicardipine), together these results argue against arterial narrowing being the sole cause of DCI. Given these findings, there is a clear need to investigate other mechanisms which may promote cerebral ischaemia following SAH. These include early brain injury (EBI), microvascular spasm, microthrombosis, spreading cortical depolarisations and failure of cerebral autoregulation (figure 3). ${ }^{83} 84$

\section{EARLY BRAIN INJURY}

Recent reports suggest that events occurring before the onset of vasospasm, during the first $72 \mathrm{~h}$ after the ictus may significantly contribute to outcome following SAH. ${ }^{85-93}$ EBI includes the primary injury resulting from the ictus as well as its direct consequences.

It has been demonstrated in experimental and clinical studies that aneurysm rupture is accompanied by a severe rise of intracranial pressure, often to suprasystolic levels, ${ }^{94} 95$ caused by extravasation of arterial blood into the subarachnoid spaces, as well as a vasodilatory cascade. ${ }^{91} 9697$ Intracranial hypertension leads to a decrease in cerebral perfusion pressure, and ultimately to cessation of cerebral blood flow (clinically manifested as syncope or loss of consciousness), and in consequence, global ischaemia, and later oedema. ${ }^{92} 9398$ Another mechanism which leads to increases of intracranial pressure and reductions of cerebral blood flow is CSF outflow obstruction and acute as well as chronic hydrocephalus. Hydrocephalus may also contribute, at least partially, to the early haemodynamic disturbances and, hence, EBI.
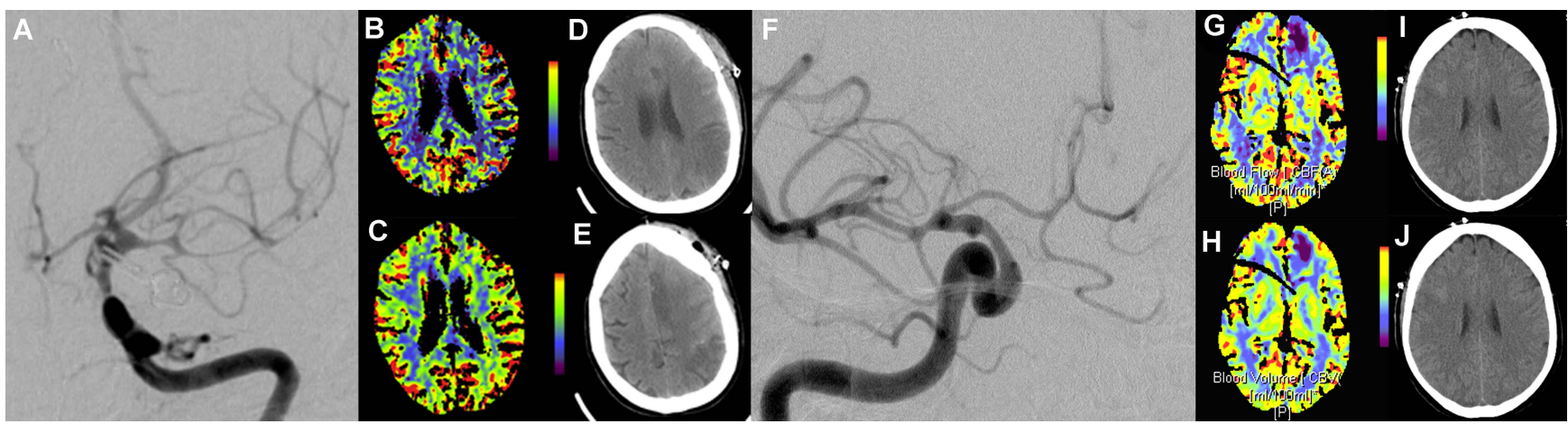

Figure 2 (A) Cerebral angiogram of a patient with WFNS 1, Fisher 3 SAH from a ruptured left PComA aneurysm (left ICA injection) performed on day 6 postictus, demonstrates diffuse severe vasospasm in the left ICA, ACA and MCA. (B) Perfusion CT performed same day shows mild reduction in $C B F$ with (C). a compensatory increase in CBV indicative of autoregulatory vasodilatation. (D and $E)$ CT on day 12 demonstrates delayed infarcts in the ACA and MCA territories. (F) Cerebral angiogram of a patient with WFNS 2, Fisher 3 SAH from a ruptured right AChA aneurysm (right ICA injection) performed on day 8 postictus, demonstrates segmental vasospasm in the right ICA and MCA, as well as diffuse vasospasm in ACAs bilaterally. ( $G$ and $H$ ) Perfusion $C T$ scan performed on the same day, demonstrates a perfusion deficit only in the left ACA territory only in CBF and CBV. (I and J) Delayed CT did not demonstrate any hypodensities. ACA, anterior cerebral artery, AChA, anterior choroidal artery; CBF, cerebral blood flow; CBV, cerebral blood volume, ICA, internal carotid artery, MCA, middle cerebral artery, SAH, subarachnoid haemorrhage; WFNS, World Federation of Neurosurgical Societies. 


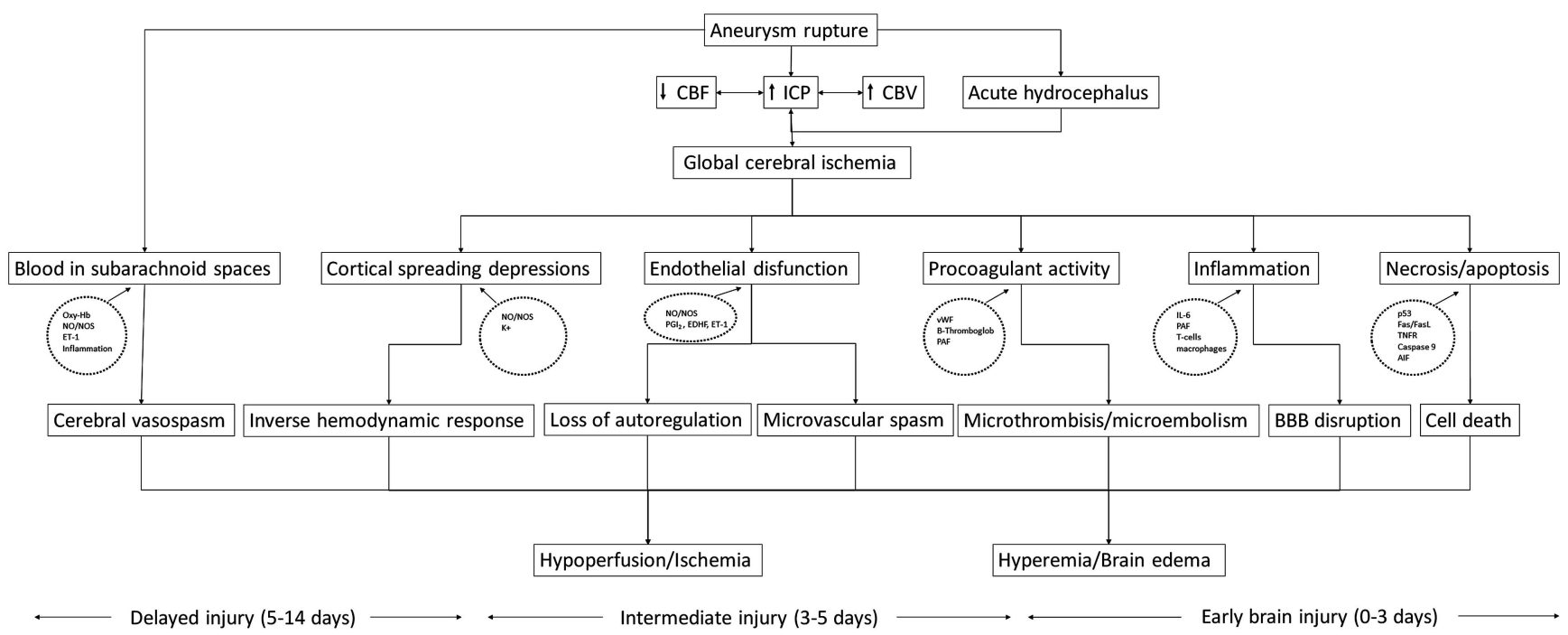

Figure 3 Diagram depicting the possible pathophysiological pathways which may lead to development of DCI. The time ranges at bottom depict approximate/presumed periods when the various processes occur. At present, it is unknown which of the mechanisms is the main culprit, however, the paradigm is shifting away from cerebral vasospasm. AIF, apoptosis inducing factor; CBF, cerebral blood flow; CBV, cerebral blood volume; EDHF, endothelial derived hyperpolarising factor; ET-1, endothelin 1; FasL, Fas ligand; ICP, intracranial pressure; IL-6, interleukin 6; NO, nitric oxide; NOS, nitric oxide synthetase; Oxy-Hb, oxyhaemoglobin; PAF, platelet-activating factor; PGI2, prostacycline; TNFR, tumour necrosis factor receptor; vWF, von Willebrand factor; DCl, delayed cerebral ischaemia. (Based on refs. 90, 94, 95, 99).

Global cerebral ischaemia, which occurs in the acute phase of $\mathrm{SAH}$, has been shown to activate several key pathophysiological pathways which, in consequence, may lead to direct nervous tissue injury as well as increased tissue vulnerability to secondary insults. These include initiation of cell death mechanisms, ${ }^{90}{ }^{99}$ blood-brain barrier disruption, ${ }^{100} 101$ an acute inflammatory response, ${ }^{102} 103$ all of which contribute to development of cerebral oedema, ${ }^{104}$ which itself is a poor prognostic factor. ${ }^{85} 105106$ Furthermore, the acute haemodynamic compromise may lead to microvascualr spasm ${ }^{63} 107108$ and microthrombosis, ${ }^{107} 109 \quad 110$ as well as failure of cerebral autoregulation (figure 3). ${ }^{62} 111-114$ All these processes are potential players in perpetuating ischaemic injury after $\mathrm{SAH}$, potentially contributing to the delayed manifestation when sufficient insults have occurred. The mechanisms implicated in DCI, along with the relevant publications are summarised in online supplementary table S1.

\section{OXIDATIVE STRESS}

Experimental and clinical evidence exist supporting the role of free radicals and oxidative stress in SAH. ${ }^{15-122}$ Generation of free radicals is related to auto-oxidation of haemoglobin in the CSF, altered mitochondrial function, lipid peroxidation, as well as NADPH oxidase function. ${ }^{123}$ Studies showed that generation of free radicals is important in the pathogenesis of CVS as well as DCI. ${ }^{115} 116119120122$ Human data indicates an increase in oxidative stress and lipid peroxidation in serum as well as CSF within 3 days after SAH. ${ }^{115} 118{ }^{119}{ }^{120}$ Furthermore, the increases are more pronounced in patients who developed $\mathrm{DCI}^{115} 116$ and those with poor neurological outcome. ${ }^{119} 120$ Markers of CSF lipid peroxidation peaked at day 6, suggesting a temporal relationship with DCI. ${ }^{115}$ However, due to the lack of simultaneous clinical correlation it is difficult to judge whether they precipitated of were a consequence of ischaemia. Nevertheless, in transgenic animal models it was demonstrated that an increase in the antioxidant capabilities leads to a reduction in apoptotic cell death after SAH. ${ }^{122}$

\section{CELL DEATH, BLOOD-BRAIN BARRIER BREAKDOWN AND INFLAMMATION}

Experimental data looking at cell death mechanisms is largely derived from experimental animal work due to the difficulty with available technology to image these processes in vivo. It has been demonstrated that neuronal cell death occurs within $24 \mathrm{~h}$ after SAH. ${ }^{124}{ }^{125}$ Necrosis, apoptosis and autophagy have all been described in animal models, often simultaneously. ${ }^{126} 127$ Intrinsic, caspase-dependent pathways have been shown to be activated as early as $40 \mathrm{~min}$ after SAH. ${ }^{128}{ }^{129}$ Activation of proapoptotic proteins, such as Bak, Bax, Bad and Bcl-XS is present, as well as activation of caspases 3,8 and $9 .{ }^{130131}$ On the other hand, while the early concepts and descriptions of the involved mechanisms of blood-brain barrier breakdown and neuroinflammation arise from experimental models, there have been a number of studies investigating these processes in humans using imaging and monitoring techniques. Blood-brain barrier breakdown and inflammation have also been reported in the acute phases after SAH. Animal models demonstrated that neutrophils can accumulate in cerebral vessels within $10 \mathrm{~min}$ after experimental SAH. ${ }^{132}$ Clinical studies looked at the major proinflammatory cytokines, for example, IL-1 $\beta$, IL-6, IL-1 receptor and TNFalfa, and found that they are increased in the CSF within 3 days after SAH. ${ }^{133}$ Their increase has been associated with unfavourable outcome, vascular spasm, as well as hyperthermia.

\section{MICROVASCULAR SPASM}

A study by Yundt et al ${ }^{134}$ demonstrated a diminished vasodilatory capacity of the cerebral microcirculation in patients who sustained SAH. Furthermore, data from experimental studies, where direct observations of small intraparenchymal and pial arterioles was performed, suggested the presence of microvascular spasm in two different experimental models of SAH. ${ }^{135-137}$ Ohkuma et $a l^{136}$ performed serial morphometric analyses of cerebral microvessels after cisternal blood injection, and demonstrated maximal luminal narrowing between days 3 and 7 . 
Similar findings were reported in vivo in mice subjected to experimental SAH. ${ }^{107}$ In vivo microvascular spasm assessed using the cerebral circulation time on angiography showed that if present within the first $24 \mathrm{~h}$, it might be predictive of subsequent large vessel vasospasm and DCI. ${ }^{108}$ Furthermore, it was demonstrated that regional reductions in cerebral blood flow are better correlated with narrowing in the microvascular compartment than with narrowing of large cerebral arteries. ${ }^{63}$ These observations argue that microvascular constriction, or the lack of microvascular dilatation may play a role in the development of DCI. The presence of microvascular spasm, not readily visible on catheter angiography, or transcranial Doppler may account for the observed discrepancies between imaging and clinical symptoms.

\section{MICROTHROMBOSIS}

It has been shown that the levels of blood coagulation markers correlate with development of DCI. ${ }^{138} 139140141142$ Procoagulant activity has been shown to precede DCI, with increased levels of platelet-activating factors noted on day 4 post-SAH, ${ }^{143}$ an increase in the von Willebrand factor seen as early as $72 \mathrm{~h}$ after the ictus, ${ }^{138}$ and loss of collagen type IV (a component of the basal lamina). ${ }^{109}$ These changes were accompanied by platelet aggregation in parenchymal vessels, which was seen as early as $10 \mathrm{~min}$ after experimental SAH. ${ }^{109} 110$ Interestingly, the timing of aggregate clearance is inconsistent with one study reporting reperfusion at $24 \mathrm{~h},{ }^{109}$ while in another, the peak intensity of platelet aggregation at the same time point. ${ }^{110}$ Importantly, microthrombi have also been found on autopsy of patients with SAH confirming that microthromboemboli are indeed a part of the clinical picture following SAH, in humans. ${ }^{144}$

Antifibrinolitic therapy with tranexamic acid resulted in a significant reduction in the rate of rebleeding following SAH. ${ }^{145-148}$ However, the benefit may have been counteracted by the increased incidence of DCI, which was not associated with large vessel spasm. These findings lead researchers to believe that the changes in coagulation homeostasis induced by tranexamic acid (causing microthrombosis) may have promoted DCI. ${ }^{149}$

A large systematic review and a meta-analysis performed by Darhout Mees and colleagues ${ }^{150} 151$ demonstrated that administration of antiplatelet medications after $\mathrm{SAH}$ reduces the relative risk (RR) of DCI by $15 \%$, and shows a non-significant trend towards improved outcomes. Nevertheless, a benefit on outcome was not demonstrated, hence routine use is not recommended.

\section{CORTICAL SPREADING DEPOLARISATION}

Cortical spreading depolarisation is an abrupt electrical change with near-complete and sustained depolarisation of a neuron or group of neurons, which has a tendency to spread through the cortex, and is associated with hyperaemia. However, when clustered or affecting injured tissue cortical spreading depolarisations are associated with metabolic, biochemical and morphological dysfunction of brain parenchyma, manifested as hypoperfusion, cytotoxic oedema and hypoxia. ${ }^{152} 153$ Cortical spreading depressions do not normally occur in uninjured brain, however, they have been implicated in the pathophysiology of migraine. Spreading depolarisations have been observed in poor grade patients following SAH. ${ }^{154-156}$

A multicenter observational study where invasive electrocorticography was performed, the CoOperative Study on Brain Injury Depolarisations (COSBID) demonstrated that clusters of spreading depolarisation are associated, and precede, development of DCI in the absence of vascular spasm. ${ }^{156}$ The proposed mechanism responsible for propagation of DCI in these cases is thought to be an inverted haemodynamic response. In normal circumstances, a wave of spreading depolarisation is accompanied by a hyperaemic response. ${ }^{154}$ With repeated waves, this hyperaemic response is diminished, and a vasoconstrictive reaction is observed with a decreased regional cerebral blood flow and oxygen supply. ${ }^{154} 157$ The mechanism for the inverted haemodynamic reaction remains poorly understood. In particular, it is unclear whether the mechanism responsible for vasoconstriction and vasodilatation during waves of depolarisations are the same as for vasomotor reactions in response to chemical and pressure stimuli.

\section{CEREBRAL AUTOREGULATION}

Experimentally, CVS does not reduce distal cerebral blood flow unless there is an additional insult, such as a fall in blood pressure. ${ }^{158}$ This finding supports Harper's dual-control hypothesis, ${ }^{159-161}$ whereby proximal arterial spasm may be compensated by distal autoregulatory vasodilatation. However, there is a limit to such compensatory mechanisms, which is why a second insult, such as a drop in perfusion pressure or increased metabolic needs, results in insufficient blood and nutrient supply leading to ischaemia. With impaired autoregulatory mechanisms (figure 4), even a single insult, such as vessel narrowing or haemodynamic instability, may lead to significant drop in blood flow rendering the brain at an increased risk of ischaemia. Evaluation of cerebral autoregulation is being increasingly recognised as a factor requiring consideration in the management of patients with SAH. ${ }^{112} 114113 \quad 162-164$ Three recent prospective studies have demonstrated that indirect indices of cerebral autoregulation can be used to prognosticate DCI as well as long-term outcome after SAH. ${ }^{112} 113163164165$ Importantly, autoregulation was found to deteriorate before clinical symptoms as well as radiographically identifiable arterial narrowing. ${ }^{163}$ Whether treatment interventions can be used to alter the state of autoregulation is unknown. In a phase II randomised

curve to complete loss of autoregulation. AR, autoregulation; CBF, cerebral blood flow; CPP, cerebral perfusion pressure. 
study of 80 patients, it was demonstrated that treatment with pravastatin shortens the duration of autoregulatory impairment. ${ }^{166} 167$ While a reduction in vasospasm and DCI was also observed, there was no effect on 6-month outcome. ${ }^{168}$

\section{TREATMENT OF DCI}

DCI, where insufficiency of blood and nutrient supply to the brain is present, may in consequence lead to infarction, permanent deficits and ultimately poor functional outcome. Despite the multiple mechanism involved, therapy has been largely targeting large vessel spasm. The following sections aim to summarise the current treatment strategies, for which human data is available. The available randomised controlled trials RCTs are delineated in online supplementary table 2 .

\section{Clearance of subarachnoid spaces}

Blood degradation products are thought to be one of the principal mechanisms responsible for development of vasospasm, ${ }^{22} 2324$ suggesting that rapid clearance of blood from subarachnoid spaces may have beneficial effects. Numerous methods have been investigated, including continuous cisternal drainage, lumbar drainage, as well as intrathecal administration of thrombolytics There are reports suggesting good success rates in decreasing the incidence of DCI with continuous cisternal drainage, however, a RCT has not been performed. ${ }^{169}$ Results from the first single-centre trial of early, continuous lumbar drainage hold promise, with a significant decrease in the incidence of DCI from $35 \%$ to only $21 \% .{ }^{170}$ However, the study failed to demonstrate any long-term benefit in outcome. Another trial aiming to recruit 300 patients is currently ongoing (clinicaltrials.gov; NCT01258257). ${ }^{171}$

Five RCTs have evaluated the use of intrathecal thrombolytic agents to clear subarachnoid blood. ${ }^{172-176} \mathrm{~A}$ meta-analysis of these studies suggests a reduction in the incidence of DCI, as well as improvements in outcome. ${ }^{177}$ However, the benefit failed to reach statistical significance after exclusion of one study where concomitant intrathecal nimodipine was administered. ${ }^{174}$

\section{Systemic targeting of angiographic vasospasm}

Nimodipine, a calcium channel blocker, is the only drug approved for use in SAH, and is the mainstay of treatment. ${ }^{178}$ In a meta-analysis, it has been shown to reduce the risk of poor outcome, with a RR of $0.7 .^{81}$ While traditionally nimodipine has been thought to prevent CVS, vascular narrowing on angiography was not included as an outcome measure in the largest trial. ${ }^{80}$ Other RCTs have demonstrated that nimodipine does not have an effect on angiographic vasospasm despite the beneficial effect on outcome, suggesting a different mechanism. ${ }^{82}$ In vitro and in vivo research demonstrates that nimodipine may have an effect on the whole vasculature, inhibiting contractions induced by noradrenaline and serotonin, potassium membrane depolarisation, as well as PGF2alfa. ${ }^{179}$ Furthermore, nimodipine has been also described to increase the fibrynolitic activity by decreasing the level of plasminogen activator inhibitor-1 (PAI-1). ${ }^{180}$

Nicardpine has been evaluated in a large, multicenter RCT in the USA-Cooperative Aneurysm Study. ${ }^{79}$ The advantage of nicardipine was the ease of preparation of the intravenous formula to be administered continuously. The study demonstrated a significant reduction of vasospasm from $46 \%$ to $32 \%$. However, there was no benefit on outcome, with an increased number of systemic complications, such as pulmonary oedema and metabolic derangements in the treatment group.

Another vasodilatator which has been studied in SAH is fasudil. Fasudil is a potent RhoA/Rho kinase (ROCK) inhibitor, which is also thought to inhibit the action of free intracellular calcium, as well as inhibit protein kinases A, G and C, and myosin light-chain directly. Fasudil has been repeatedly shown to have beneficial effects on development of CVS, delayed cerebral infarcts as well as outcome. ${ }^{181}$ Furthermore, fasudil has been compared with nimodipine (although intravenous rather than oral) demonstrating improved outcome. ${ }^{182}$ A large multicenter study is yet to be conducted.

Cilostazol, a phosphodiesterase 3 inhibitor is a platelet aggregation inhibitor, which also has an effect on smooth muscle cells. ${ }^{183}$ Cilostazol has been shown to ameliorate vasospasm in experimental models. ${ }^{184}$ Two RCTs were conducted evaluating the use of cilostazol in SAH. One study demonstrated a benefit on DCI and outcome at discharge. ${ }^{185}$ The second study showed a reduction in the risk of vasospasm and cerebral infarction, without improvements in outcome. ${ }^{186}$ In a meta-analysis, which additionally included two non-RCT, a benefit on outcome at discharge was demonstrated (also when the non-RCT studies were excluded). ${ }^{187}$ Importantly, only one study reported longterm outcomes, which did not differ between groups. ${ }^{186}$

Endothelins, potent vasoconstrictors, have been implicated in CVS. ${ }^{49} 5051$ An endothelin A receptor antagonist, clazosentan has been shown in experimental as well as clinical studies to ameliorate vasospasm. ${ }^{53} 54555758$ However, in a large multicentre, phase III study, no improvement in outcome could be shown. ${ }^{56}$ Similarly to nicardipine, patients receiving the drug suffered from a large number of systemic complications.

\section{Local delivery}

Administration of drugs targeting vasospasm is frequently hampered by systemic complications, a factor that has generated interest in local delivery methods. At present, the only locally delivered substance for which clinical data exist is nicardipine administered into the subarachnoid spaces as prolonged-release implants. Preliminary data comes from an open-label trial in Japan $(n=97)$, where a decrease of the incidence of DCI was noted from $11 \%$ to $6 \% .{ }^{188}$ Subsequently, in a single centre RCT $(\mathrm{n}=32)$, nicardipine implants were found to significantly decrease the incidence of vasospasm (73\% vs 7\%), delayed infarcts $(47 \%$ vs $14 \%)$, as well as improved outcome $(38 \%$ vs $6 \%) .{ }^{189}$ Notably, the study was conducted only on poor-grade SAH patients, hence, the generalisability and robustness of the results remains uncertain. Currently, no phase III study has confirmed the significance of the initial findings.

Prophylactic balloon angioplasty has not been shown in a multicentre phase II study to be beneficial following SAH. ${ }^{190}$ Therapeutic balloon angioplasty and intra-arterial vasodilators, while used in some patients when medical management has failed, are only now being studied in a randomised trialDiagnostic and Therapeutic Management of Cerebral Vasospasm After Aneurysmatic Subarachnoid Haemorrhage (IMCVS) (clinicaltrials.gov; NCT01400360).

\section{Drugs with multidirectional effects/neuroprotection}

Statins, which have been shown to have diverse clinical effects, have been evaluated in four single-centre RCTs with mixed results. $^{166} 168$ 191-193 A meta-analysis of the trials has so far demonstrated no benefit from using this treatment. ${ }^{11}$ However, a multicentre study of simvastatin is currently ongoing (clinicaltrials.gov; NCT00731627), with another one comparing high dose vs low dose (clinicaltrials.gov; NCT01077206). Interestingly, statins have been shown to reduce the duration of impaired autoregulation after $\mathrm{SAH}$, which has been implicated as a potential mechanism of action. ${ }^{166}$ 
Magnesium is another compound with neuroprotective effects which has been assessed in SAH. ${ }^{194}$ The interest in magnesium sparked from an observation that hypomagnesemia may be associated with increased incidence of DCI. ${ }^{195}$ However, the results from the largest multicentre study and a meta-analysis failed to demonstrate a significant difference in outcome. ${ }^{196}$

The neuroprotective effects of erythropoietin (EPO) have been studied in experimental models. ${ }^{197}{ }^{198}$ Furthermore, EPO has been shown to ameliorate vasospasm and improve outcome after experimental SAH. ${ }^{199}$ Tseng, ${ }^{200}$ in a single-centre study demonstrated that, similar to statins, EPO treatment was associated with a reduced duration of impaired autoregulation, a lower incidence of severe vasospasm and DCI, as well as an improved outcome at discharge. However, long-term benefits were not demonstrated.

Albumin, 25\%, has been shown to be neuroprotective. ${ }^{201} \mathrm{~A}$ pilot study of human albumin demonstrated a good tolerability. Results from phase III RCT are awaited.

\section{Microthrombosis}

The findings that SAH leads to clotting activation (physiological mechanism to prevent rebleeding), platelet aggregation and microthrombosis lead to design of studies of antiplatelet agents. Nevertheless, despite solid pathophysiological background, the results of the studies have been largely negative. ${ }^{151}$ Similarly, the role of low molecular weight heparin in the prevention of microthrombosis has been investigated in two RCTs. Results of the studies were mixed, with one demonstrating a lack of effect on outcome and four cases of intracranial bleeding thought to be related to the treatment. ${ }^{202}$ By contrast, another study found a beneficial effect of enoxaparin on vasospasm, DCI as well as outcome, with fewer haemorrhagic complication in the treated group. ${ }^{203}$ However, the results need to be treated with caution, as groups were not well matched for admission grade.

\section{Free radicals and inflammation}

Tirilizad mesylate, a non-glucocorticoid, 21-aminosteriod that inhibits lipid peroxidation, has been evaluated in four RCTs with mixed results. ${ }^{204-207}$ However, two meta-analyses demonstrated no effect on DCI, infarcts, or outcome. ${ }^{208} 209$

Three studies investigated the effect of free radical scavengers on DCI and outcome after SAH. ${ }^{210-212}$ Ebselen was found to improve outcome in a large study of 286 patients. Interestingly, the improvement in outcome was independent of the incidence of DCI which was unchanged between the treatment and placebo groups. ${ }^{211}$ Similarly, two other free-radical scavengers, nicaraven and edaravone, have been proven to be beneficial, after SAH. ${ }^{210} 212$

Several anti-inflammatory compounds have been studied after SAH. Suzuki, ${ }^{213}$ used a synthetic thromboxane synthetase inhibitor, OKY-046, to prevent DCI. They demonstrated reduction of DCI and improvement in outcome at 1 year. ${ }^{213}$ Methylprednisolone, a strong immunosuppressant, was shown in a randomised study to significantly improve outcome without any effect on vasospasm. ${ }^{214}$

Despite these promising results, none of the investigated compounds have been assessed in multicenter studies nor implemented in clinical practice.

\section{CONCLUSIONS}

Outcome form SAH has improved in the last 20 years. This is most likely due to early aneurysm repair, intensive management, and routine use of nimodipine. However, the exact influence of management of DCI on outcome is unclear. This is further complicated by the wide differences in the incidence of DCI, with some studies suggesting an incidence around 15-20\%, while others as high as 40\%. Despite new data and increased understating of the pathophysiology of SAH, DCI as well as EBI, no new treatments have been introduced since nimodipine. Data from large randomised controlled studies suggests that a pure focus on CVS, as the sole cause of DCI and poor outcome, is misguided. Nevertheless, the available data does not yet support other approaches aimed at mechanisms distinct form vasospasm, such as microthrombosis and platelet aggregation, inflammation and formation of free radicals. Consequently, current management strategies frequently focus on intensive care management with widespread use of pharmacological and interventional rescue therapies. While numerous targets are still being investigated, some of the more promising results come from drugs with multifactorial effects, such as statins or cilostazol. Overall, available data suggests that a focus on a single pathway may not be sufficient to improve outcomes in SAH. Furthermore, design of future clinical trials should take notice of the available findings and construct studies with appropriate selection of high-risk patients, as well as adequately sensitive and objective outcome measures. Similarly, studies which failed to demonstrate outcome benefits, where sound physiological data exist, should be re-evaluated with the aim of explaining the reason for futility, helping to define the patient groups which could benefit as well as provide background for future drug development.

Contributors KPB: first draft, literature search, approved final version. MG: review of first draft and critical comments, approved final version. AH: review of first draft and critical comments, approved final version. TH: review of first draft and critical comments, approved final version. MC: review of first draft and critical comments, approved final version. RK: review of first draft and critical comments, approved final version. DKM: review of first draft and critical comments, approved final version. JDP: review of first draft and critical comments, approved final version, supervised project. PJK: review of first draft and critical comments, approved final version, supervised project

Competing interests None.

Provenance and peer review Not commissioned; externally peer reviewed.

\section{REFERENCES}

1 Linn FH, Rinkel GJ, Algra A, et al. Incidence of subarachnoid hemorrhage: role of region, year, and rate of computed tomography: a meta-analysis. Stroke 1996:27:625-9.

2 ACROSS. Epidemiology of aneurysmal subarachnoid hemorrhage in Australia and New Zealand: incidence and case fatality from the Australasian Cooperative Research on Subarachnoid Hemorrhage Study (ACROSS). Stroke 2000;31:1843-50.

3 Johnston SC, Selvin S, Gress DR. The burden, trends, and demographics of mortality from subarachnoid hemorrhage. Neurology 1998;50:1413-18.

4 Lovelock CE, Rinkel GJ, Rothwell PM. Time trends in outcome of subarachnoid hemorrhage: population-based study and systematic review. Neurology 2010;74:1494-501.

5 Komotar RJ, Schmidt JM, Starke RM, et al. Resuscitation and critical care of poorgrade subarachnoid hemorrhage. Neurosurgery 2009;64:397-410; discussion 410-1.

6 Hop JW, Rinkel GJ, Algra A, et al. Case-fatality rates and functional outcome after subarachnoid hemorrhage: a systematic review. Stroke 1997;28:660-4.

7 Hop JW, Rinkel GJ, Algra A, et al. Quality of life in patients and partners after aneurysmal subarachnoid hemorrhage. Stroke 1998;29:798-804

8 Rabinstein AA, Friedman JA, Weigand SD, et al. Predictors of cerebral infarction in aneurysmal subarachnoid hemorrhage. Stroke 2004;35:1862-6.

9 Hijdra A, Van Gijn J, Stefanko S, et al. Delayed cerebral ischemia after aneurysmal subarachnoid hemorrhage: clinicoanatomic correlations. Neurology 1986:36:329-33.

10 Rosengart AJ, Schultheiss KE, Tolentino J, et al. Prognostic factors for outcome in patients with aneurysmal subarachnoid hemorrhage. Stroke 2007:38:2315-21.

11 Vergouwen MD, de Haan RJ, Vermeulen $\mathrm{M}$, et al. Effect of statin treatment on vasospasm, delayed cerebral ischemia, and functional outcome in patients with aneurysmal subarachnoid hemorrhage: a systematic review and meta-analysis update. Stroke 2010:41:e47-52.

12 Ecker A, Riemenschneider PA. Arteriographic demonstration of spasm of the intracranial arteries, with special reference to saccular arterial aneurysms. I Neurosurg 1951;8:660-7.

13 Allcock JM, Drake CG. Postoperative angiography in cases of ruptured intracranial aneurysm. J Neurosurg 1963:20:752-9. 
14 Harders AG, Gilsbach JM. Time course of blood velocity changes related to vasospasm in the circle of Willis measured by transcranial Doppler ultrasound. J Neurosurg 1987;66:718-28.

15 Carrera E, Schmidt JM, Oddo M, et al. Transcranial Doppler for predicting delayed cerebral ischemia after subarachnoid hemorrhage. Neurosurgery 2009;65:316-23; discussion 323-4.

16 Crowley RW, Medel R, Dumont AS, et al. Angiographic vasospasm is strongly correlated with cerebral infarction after subarachnoid hemorrhage. Stroke 2011:42:919-23.

17 Fisher CM, Roberson GH, Ojemann RG. Cerebral vasospasm with ruptured saccular aneurysm-the clinical manifestations. Neurosurgery 1977;1:245-8.

18 Grosset DG, Straiton J, du Trevou M, et al. Prediction of symptomatic vasospasm after subarachnoid hemorrhage by rapidly increasing transcranial Doppler velocity and cerebral blood flow changes. Stroke 1992:23:674-9.

19 Fisher CM, Kistler JP, Davis JM. Relation of cerebral vasospasm to subarachnoid hemorrhage visualized by computerized tomographic scanning. Neurosurgery 1980;6:1-9.

20 Claassen J, Bernardini GL, Kreiter K, et al. Effect of cisternal and ventricular blood on risk of delayed cerebral ischemia after subarachnoid hemorrhage: the Fisher scale revisited. Stroke 2001;32:2012-20.

21 Hijdra A, van Gijn J, Nagelkerke NJ, et al. Prediction of delayed cerebral ischemia, rebleeding, and outcome after aneurysmal subarachnoid hemorrhage. Stroke 1988;19:1250-6

22 Macdonald RL, Weir BK. A review of hemoglobin and the pathogenesis of cerebral vasospasm. Stroke 1991:22:971-82.

23 Macdonald RL, Weir BK, Runzer TD, et al. Etiology of cerebral vasospasm in primates. J Neurosurg 1991;75:415-24.

24 Buckell M. Demonstration of Substances Capable of Contracting Smooth Muscle in the Haematoma Fluid from Certain Cases of Ruptured Cerebral Aneurysm. J Neurol Neurosurg Psychiatry 1964;27:198-9.

25 Toda N, Shimizu K, Ohta T. Mechanism of cerebral arterial contraction induced by blood constituents. J Neurosurg 1980;53:312-22.

26 Toda N. Mechanisms of contracting action of oxyhemoglobin in isolated monkey and dog cerebral arteries. Am J Physiol 1990;258(1 Pt 2):H57-63.

27 Macdonald RL, Weir BK, Grace MG, et al. Morphometric analysis of monkey cerebral arteries exposed in vivo to whole blood, oxyhemoglobin, methemoglobin, and bilirubin. Blood Vessels 1991;28:498-510.

28 Doczi T. The pathogenetic and prognostic significance of blood-brain barrier damage at the acute stage of aneurysmal subarachnoid haemorrhage. Clinical and experimental studies. Acta Neurochir (Wien) 1985;77:110-32.

29 Doczi T, Joo F, Adam G, et al. Blood-brain barrier damage during the acute stage of subarachnoid hemorrhage, as exemplified by a new animal model. Neurosurgery 1986:18:733-9.

30 Doczi T, Joo F, Sonkodi S, et al. Increased vulnerability of the blood-brain barrier to experimental subarachnoid hemorrhage in spontaneously hypertensive rats. Stroke 1986;17:498-501.

31 Pradilla G, Chaichana KL, Hoang S, et al. Inflammation and cerebral vasospasm after subarachnoid hemorrhage. Neurosurg Clin N Am 2010;21:365-79.

32 Fassbender $\mathrm{K}$, Hodapp B, Rossol $\mathrm{S}$, et al. Endothelin-1 in subarachnoid hemorrhage: An acute-phase reactant produced by cerebrospinal fluid leukocytes. Stroke 2000;31:2971-5.

33 Fassbender K, Hodapp B, Rossol S, et al. Inflammatory cytokines in subarachnoid haemorrhage: association with abnormal blood flow velocities in basal cerebral arteries. J Neurol Neurosurg Psychiatry 2001;70:534-7.

34 Griffith TM, Edwards DH, Lewis MJ, et al. The nature of endothelium-derived vascular relaxant factor. Nature 1984:308:645-7.

35 Furchgott RF, Zawadzki JV. The obligatory role of endothelial cells in the relaxation of arterial smooth muscle by acetylcholine. Nature 1980;288:373-6.

36 Sehba FA, Schwartz AY, Chereshnev I, et al. Acute decrease in cerebral nitric oxide levels after subarachnoid hemorrhage. J Cereb Blood Flow Metab 2000;20:604-11.

37 Khaldi A, Zauner A, Reinert $M$, et al. Measurement of nitric oxide and brain tissue oxygen tension in patients after severe subarachnoid hemorrhage. Neurosurgery 2001:49:33-8; discussion 38-40.

38 Kim P, Lorenz RR, Sundt TM Jr, et al. Release of endothelium-derived relaxing factor after subarachnoid hemorrhage. J Neurosurg 1989:70:108-14.

39 Pluta RM, Thompson BG, Dawson TM, et al. Loss of nitric oxide synthase immunoreactivity in cerebral vasospasm. J Neurosurg 1996;84:648-54.

40 Iuliano BA, Pluta RM, Jung $C$, et al. Endothelial dysfunction in a primate model of cerebral vasospasm. J Neurosurg 2004;100:287-94

41 Hino A, Tokuyama $Y$, Weir $B$, et al. Changes in endothelial nitric oxide synthase mRNA during vasospasm after subarachnoid hemorrhage in monkeys. Neurosurgery 1996:39:562-7; discussion 567-8.

42 Jung $\mathrm{CS}$, Oldfield EH, Harvey-White J, et al. Association of an endogenous inhibitor of nitric oxide synthase with cerebral vasospasm in patients with aneurysmal subarachnoid hemorrhage. J Neurosurg 2007;107:945-50.

43 Nishizawa S, Yamamoto S, Yokoyama T, et al. Chronological changes of arterial diameter, CGMP, and protein kinase $C$ in the development of vasospasm. Stroke 1995;26:1916-20; discussion 1920-1.
44 Nishizawa S, Yamamoto S, Yokoyama T, et al. Dysfunction of nitric oxide induces protein kinase $C$ activation resulting in vasospasm after subarachnoid hemorrhage. Neurol Res 1997:19:558-62.

45 Pluta RM, Oldfield EH, Boock RJ. Reversal and prevention of cerebral vasospasm by intracarotid infusions of nitric oxide donors in a primate model of subarachnoid hemorrhage. J Neurosurg 1997;87:746-51.

46 Raabe A, Zimmermann M, Setzer M, et al. Effect of intraventricular sodium nitroprusside on cerebral hemodynamics and oxygenation in poor-grade aneurysm patients with severe, medically refractory vasospasm. Neurosurgery 2002:50:1006-13; discussion 1013-4.

47 Pluta RM. Delayed cerebral vasospasm and nitric oxide: review, new hypothesis, and proposed treatment. Pharmacol Ther 2005;105:23-56.

48 Pluta RM, Oldfield EH, Bakhtian KD, et al. Safety and feasibility of long-term intravenous sodium nitrite infusion in healthy volunteers. PLOS ONE 2011;6: e14504.

49 Suhardja A. Mechanisms of disease: roles of nitric oxide and endothelin-1 in delayed cerebral vasospasm produced by aneurysmal subarachnoid hemorrhage. Nat Clin Pract Cardiovasc Med 2004;1:110-16; quiz 2 p following 116.

50 Juvela S. Plasma endothelin concentrations after aneurysmal subarachnoid hemorrhage. J Neurosurg 2000;92:390-400.

51 Seifert V, Loffler BM, Zimmermann $\mathrm{M}$, et al. Endothelin concentrations in patients with aneurysmal subarachnoid hemorrhage. Correlation with cerebral vasospasm, delayed ischemic neurological deficits, and volume of hematoma. J Neurosurg 1995;82:55-62

52 Mascia L, Fedorko L, Stewart DJ, et al. Temporal relationship between endothelin-1 concentrations and cerebral vasospasm in patients with aneurysmal subarachnoid hemorrhage. Stroke 2001;32:1185-90.

53 Roux S, Breu V, Giller T, et al. Ro 61-1790, a new hydrosoluble endothelin antagonist: general pharmacology and effects on experimental cerebral vasospasm. J Pharmacol Exp Ther 1997:283:1110-18.

54 Vatter $\mathrm{H}$, Zimmermann M, Tesanovic V, et al. Cerebrovascular characterization of clazosentan, the first nonpeptide endothelin receptor antagonist clinically effective for the treatment of cerebral vasospasm. Part I: inhibitory effect on endothelin(A) receptor-mediated contraction. J Neurosurg 2005:102:1101-7.

55 Macdonald RL, Higashida RT, Keller E, et al. Clazosentan, an endothelin receptor antagonist, in patients with aneurysmal subarachnoid haemorrhage undergoing surgical clipping: a randomised, double-blind, placebo-controlled phase 3 trial (CONSCIOUS-2). Lancet Neurol 2011;10:618-25.

56 Macdonald RL, Higashida RT, Keller $\mathrm{E}$, et al. Randomized trial of clazosentan in patients with aneurysmal subarachnoid hemorrhage undergoing endovascular coiling. Stroke 2012:43:1463-9.

57 Macdonald RL, Kassell NF, Mayer S, et al. Clazosentan to overcome neurological ischemia and infarction occurring after subarachnoid hemorrhage (CONSCIOUS-1): randomized, double-blind, placebo-controlled phase 2 dose-finding trial. Stroke 2008:39:3015-21.

58 Vajkoczy P, Meyer B, Weidauer S, et al. Clazosentan (AXV-034343), a selective endothelin A receptor antagonist, in the prevention of cerebral vasospasm following severe aneurysmal subarachnoid hemorrhage: results of a randomized, double-blind, placebo-controlled, multicenter phase lla study. J Neurosurg 2005:103:9-17.

59 Vergouwen MD, Algra A, Rinkel GJ. Endothelin receptor antagonists for aneurysmal subarachnoid hemorrhage: a systematic review and meta-analysis update. Stroke 2012;43:2671-6.

60 Dankbaar JW, Rijsdijk M, van der Schaaf IC, et al. Relationship between vasospasm, cerebral perfusion, and delayed cerebral ischemia after aneurysma subarachnoid hemorrhage. Neuroradiology 2009:51:813-19.

61 Hattingen E, Blasel S, Dettmann E, et al. Perfusion-weighted MRI to evaluate cerebral autoregulation in aneurysmal subarachnoid haemorrhage. Neuroradiology 2008:50:929-38.

62 Ishii R. Regional cerebral blood flow in patients with ruptured intracrania aneurysms. J Neurosurg 1979;50:587-94.

63 Ohkuma $\mathrm{H}$, Manabe $\mathrm{H}$, Tanaka $\mathrm{M}$, et al. Impact of cerebral microcirculatory changes on cerebral blood flow during cerebral vasospasm after aneurysma subarachnoid hemorrhage. Stroke 2000;31:1621-7.

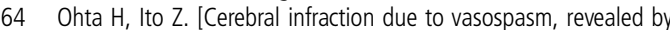
computed tomography (author's transl)]. Neurol Med Chir (Tokyo) 1981:21:365-72.

65 Vora YY, Suarez-Almazor M, Steinke DE, et al. Role of transcranial Doppler monitoring in the diagnosis of cerebral vasospasm after subarachnoid hemorrhage. Neurosurgery 1999;44:1237-47; discussion 1247-8.

66 Dehdashti AR, Mermillod B, Rufenacht DA, et al. Does treatment modality of intracranial ruptured aneurysms influence the incidence of cerebral vasospasm and clinical outcome? Cerebrovasc Dis 2004;17:53-60.

67 Weidauer S, Lanfermann $\mathrm{H}$, Raabe A, et al. Impairment of cerebral perfusion and infarct patterns attributable to vasospasm after aneurysmal subarachnoid hemorrhage: a prospective MRI and DSA study. Stroke 2007:38:1831-6.

68 Rabinstein AA, Weigand S, Atkinson JL, et al. Patterns of cerebral infarction in aneurysmal subarachnoid hemorrhage. Stroke 2005;36:992-7. 
69 Brown RJ, Kumar A, llodigwe D, et al. The relationship between delayed infarcts and angiographic vasospasm after aneurysmal subarachnoid hemorrhage. Neurosurg 2013;72:702-8

70 Kelly PJ, Gorten RJ, Grossman RG, et al. Cerebral perfusion, vascular spasm, and outcome in patients with ruptured intracranial aneurysms. J Neurosurg 1977:47:44-9.

71 Geraud G, Tremoulet M, Guell A, et al. The prognostic value of noninvasive CBF measurement in subarachnoid hemorrhage. Stroke 1984;15:301-5.

72 Simeone FA, Trepper PJ, Brown DJ. Cerebral blood flow evaluation of prolonged experimental vasospasm. J Neurosurg 1972;37:302-11.

73 Hatazawa J, lida $\mathrm{H}$, Shimosegawa $\mathrm{E}$, et al. Regional cerebral blood flow measurement with iodine-123-IMP autoradiography: normal values, reproducibility and sensitivity to hypoperfusion. J Nucl Med 1997;38:1102-8.

74 Heilbrun MP, Olesen J, Lassen NA. Regional cerebral blood flow studies in subarachnoid hemorrhage. J Neurosurg 1972;37:36-44.

75 Minhas PS, Menon DK, Smielewski P, et al. Positron emission tomographic cerebral perfusion disturbances and transcranial Doppler findings among patients with neurological deterioration after subarachnoid hemorrhage. Neurosurgery 2003; 52:1017-22; discussion 1022-4

76 Dhar R, Scalfani MT, Blackburn S, et al. Relationship between angiographic vasospasm and regional hypoperfusion in aneurysmal subarachnoid hemorrhage. Stroke 2012;43:1788-94.

77 Mir DI, Gupta A, Dunning A, et al. CT Perfusion for detection of delayed cerebral ischemia in aneurysmal subarachnoid hemorrhage: a systematic review and meta-analysis. AJNR Am J Neuroradiol 2013.

78 Etminan N, Vergouwen MD, llodigwe $\mathrm{D}$, et al. Effect of pharmaceutical treatment on vasospasm, delayed cerebral ischemia, and clinical outcome in patients with aneurysmal subarachnoid hemorrhage: a systematic review and meta-analysis. J Cereb Blood Flow Metab 2011;31:1443-51.

79 Haley EC Jr, Kassell NF, Torner JC. A randomized controlled trial of high-dose intravenous nicardipine in aneurysmal subarachnoid hemorrhage. A report of the Cooperative Aneurysm Study. J Neurosurg 1993;78:537-47.

80 Pickard JD, Murray GD, Illingworth $\mathrm{R}$, et al. Effect of oral nimodipine on cerebral infarction and outcome after subarachnoid haemorrhage: British aneurysm nimodipine trial. Bmj 1989;298:636-42.

81 Rinkel GJ, Feigin VL, Algra A, et al. Calcium antagonists for aneurysmal subarachnoid haemorrhage. Cochrane Database Syst Rev 2005;(1):CD000277.

82 Petruk KC, West M, Mohr G, et al. Nimodipine treatment in poor-grade aneurysm patients. Results of a multicenter double-blind placebo-controlled trial. J Neurosurg 1988;68:505-17.

83 Macdonald RL, Pluta RM, Zhang JH. Cerebral vasospasm after subarachnoid hemorrhage: the emerging revolution. Nat Clin Pract Neurol 2007;3:256-63.

84 Rabinstein AA. Secondary brain injury after aneurysmal subarachnoid haemorrhage: more than vasospasm. Lancet Neurol 2011;10:593-5.

85 Claassen J, Carhuapoma JR, Kreiter KT, et al. Global cerebral edema after subarachnoid hemorrhage: frequency, predictors, and impact on outcome. Stroke 2002;33:1225-32.

86 Hop JW, Rinkel GJ, Algra A, et al. Initial loss of consciousness and risk of delayed cerebral ischemia after aneurysmal subarachnoid hemorrhage. Stroke 1999;30:2268-71.

87 Schmidt JM, Rincon F, Fernandez A, et al. Cerebral infarction associated with acute subarachnoid hemorrhage. Neurocrit Care 2007:7:10-17.

88 Wartenberg KE, Sheth SJ, Michael Schmidt J, et al. Acute ischemic injury on diffusion-weighted magnetic resonance imaging after poor grade subarachnoid hemorrhage. Neurocrit Care 2011;14:407-15.

89 Broderick JP, Brott TG, Duldner JE, et al. Initial and recurrent bleeding are the major causes of death following subarachnoid hemorrhage. Stroke 1994;25:1342-7.

90 Cahill J, Calvert JW, Zhang JH. Mechanisms of early brain injury after subarachnoid hemorrhage. J Cereb Blood Flow Metab 2006;26:1341-53.

91 Grote $\mathrm{E}$, Hassler W. The critical first minutes after subarachnoid hemorrhage. Neurosurgery 1988;22:654-61.

92 Schubert GA, Seiz M, Hegewald AA, et al. Acute hypoperfusion immediately after subarachnoid hemorrhage: a xenon contrast-enhanced CT study. I Neurotrauma 2009:26:2225-31

93 Schubert GA, Seiz M, Hegewald AA, et al. Hypoperfusion in the acute phase of subarachnoid hemorrhage. Acta Neurochir Supp/ 2010;110:35-8.

94 Voldby B, Enevoldsen EM. Intracranial pressure changes following aneurysm rupture. Part 1: clinical and angiographic correlations. J Neurosurg 1982;56:186-96.

95 Nornes H. Cerebral arterial flow dynamics during aneurysm haemorrhage. Acta Neurochir (Wien) 1978;41:39-48

96 Martin WR, Baker RP, Grubb RL, et al. Cerebral blood volume, blood flow, and oxygen metabolism in cerebral ischaemia and subarachnoid haemorrhage: an in-vivo study using positron emission tomography. Acta Neurochir (Wien) 1984;70:3-9

97 Bijlenga P, Czosnyka M, Budohoski KP, et al. "Optimal cerebral perfusion pressure" in poor grade patients after subarachnoid hemorrhage. Neurocrit Care 2010;13:17-23.
98 Nornes H. The role of intracranial pressure in the arrest of hemorrhage in patients with ruptured intracranial aneurysm. J Neurosurg 1973;39:226-34.

99 Hasegawa Y, Suzuki H, Sozen T, et al. Apoptotic mechanisms for neuronal cells in early brain injury after subarachnoid hemorrhage. Acta Neurochir Supp/ 2010;110:43-8

100 Scholler K, Trinkl A, Klopotowski M, et al. Characterization of microvascular basal lamina damage and blood-brain barrier dysfunction following subarachnoid hemorrhage in rats. Brain Res 2007;1142:237-46.

101 Thal SC, Sporer S, Schmid-Elsaesser R, et al. Inhibition of bradykinin B2 receptors before, not after onset of experimental subarachnoid hemorrhage prevents brain edema formation and improves functional outcome. Crit Care Med 2009:37:2228-34.

102 Hanafy KA, Morgan Stuart R, Fernandez L, et al. Cerebral inflammatory response and predictors of admission clinical grade after aneurysmal subarachnoid hemorrhage. J Clin Neurosci 2010;17:22-5.

103 Sozen T, Tsuchiyama R, Hasegawa Y, et al. Immunological Response in Early Brain Injury After SAH. Acta Neurochir Suppl 2011;110:57-61.

104 Laszlo FA, Varga C, Doczi T. Cerebral oedema after subarachnoid haemorrhage. Pathogenetic significance of vasopressin. Acta Neurochir (Wien) 1995; 133:122-33

105 Helbok R, Ko SB, Schmidt JM, et al. Global cerebral edema and brain metabolism after subarachnoid hemorrhage. Stroke 2011;42:1534-9.

106 Zetterling M, Hallberg L, Ronne-Engstrom E. Early global brain oedema in relation to clinical admission parameters and outcome in patients with aneurysmal subarachnoid haemorrhage. Acta Neurochir (Wien) 2010;152:1527-33; discussion 1533.

107 Friedrich B, Muller F, Feiler S, et al. Experimental subarachnoid hemorrhage causes early and long-lasting microarterial constriction and microthrombosis: an in-vivo microscopy study. J Cereb Blood Flow Metab 2012;32:447-55.

108 Udoetuk JD, Stiefel MF, Hurst RW, et al. Admission angiographic cerebral circulation time may predict subsequent angiographic vasospasm after aneurysmal subarachnoid hemorrhage. Neurosurgery 2007:61:1152-9; discussion 1159-61.

109 Friedrich V, Flores R, Muller A, et al. Luminal platelet aggregates in functional deficits in parenchymal vessels after subarachnoid hemorrhage. Brain Res 2010;1354:179-87.

110 Sehba FA, Mostafa G, Friedrich V Jr, et al. Acute microvascular platelet aggregation after subarachnoid hemorrhage. J Neurosurg 2005;102:1094-100.

111 Yamamoto S, Nishizawa S, Tsukada H, et al. Cerebral blood flow autoregulation following subarachnoid hemorrhage in rats: chronic vasospasm shifts the upper and lower limits of the autoregulatory range toward higher blood pressures. Brain Res 1998;782:194-201.

112 Jaeger $M$, Schuhmann MU, Soehle $M$, et al. Continuous monitoring of cerebrovascular autoregulation after subarachnoid hemorrhage by brain tissue oxygen pressure reactivity and its relation to delayed cerebral infarction. Stroke 2007:38:981-6.

113 Jaeger M, Soehle M, Schuhmann MU, et al. Clinical Significance of Impaired Cerebrovascular Autoregulation After Severe Aneurysmal Subarachnoid Hemorrhage. Stroke 2012;43:2097-101.

114 Lam JM, Smielewski P, Czosnyka M, et al. Predicting delayed ischemic deficits after aneurysmal subarachnoid hemorrhage using a transient hyperemic response test of cerebral autoregulation. Neurosurgery 2000;47:819-25; discussions 825-6.

115 Asaeda M, Sakamoto M, Kurosaki M, et al. A non-enzymatic derived arachidonyl peroxide, 8-iso-prostaglandin F2 alpha, in cerebrospinal fluid of patients with aneurysmal subarachnoid hemorrhage participates in the pathogenesis of delayed cerebral vasospasm. Neurosci Lett 2005;373:222-5.

116 Gaetani P, Lombardi D. Brain damage following subarachnoid hemorrhage: the imbalance between anti-oxidant systems and lipid peroxidative processes. J Neurosurg Sci 1992;36:1-10.

117 Gaetani P, Marzatico F, Rodriguez y Baena R, et al. Arachidonic acid metabolism and pathophysiologic aspects of subarachnoid hemorrhage in rats. Stroke 1990;21:328-32.

118 Gaetani P, Pasqualin A, Rodriguez y Baena $R$, et al. Oxidative stress in the human brain after subarachnoid hemorrhage. J Neurosurg 1998:89:748-54.

119 Hsieh YP, Lin CL, Shiue AL, et al. Correlation of F4-neuroprostanes levels in cerebrospinal fluid with outcome of aneurysmal subarachnoid hemorrhage in humans. Free Radic Biol Med 2009;47:814-24.

120 Kamezaki T, Yanaka K, Nagase S, et al. Increased levels of lipid peroxides as predictive of symptomatic vasospasm and poor outcome after aneurysmal subarachnoid hemorrhage. J Neurosurg 2002:97:1302-5.

121 Marzatico F, Gaetani P, Cafe C, et al. Antioxidant enzymatic activities after experimental subarachnoid hemorrhage in rats. Acta Neurol Scand 1993; 87:62-6.

122 Endo $\mathrm{H}$, Nito $\mathrm{C}$, Kamada $\mathrm{H}$, et al. Reduction in oxidative stress by superoxide dismutase overexpression attenuates acute brain injury after subarachnoid hemorrhage via activation of Akt/glycogen synthase kinase-3beta survival signaling. J Cereb Blood Flow Metab 2007;27:975-82.

123 Ayer RE, Zhang JH. Oxidative stress in subarachnoid haemorrhage: significance in acute brain injury and vasospasm. Acta Neurochir Supp/ 2008;104:33-41. 
124 Cahill J, Calvert JW, Solaroglu I, et al. Vasospasm and p53-induced apoptosis in an experimental model of subarachnoid hemorrhage. Stroke 2006;37:1868-74.

125 Prunell GF, Svendgaard NA, Alkass K, et al. Delayed cell death related to acute cerebral blood flow changes following subarachnoid hemorrhage in the rat brain. J Neurosurg 2005;102:1046-54.

126 Lee JY, He Y, Sagher O, et al. Activated autophagy pathway in experimental subarachnoid hemorrhage. Brain Res 2009;1287:126-35.

127 Matz PG, Fujimura M, Lewen A, et al. Increased cytochrome c-mediated DNA fragmentation and cell death in manganese-superoxide dismutase-deficient mice after exposure to subarachnoid hemolysate. Stroke 2001;32:506-15.

128 Gules I, Satoh M, Nanda A, et al. Apoptosis, blood-brain barrier, and subarachnoid hemorrhage. Acta Neurochir Supp/ 2003:86:483-7.

129 Yamaura I, Tani E, Saido TC, et al. Calpain-calpastatin system of canine basilar artery in vasospasm. J Neurosurg 1993;79:537-43.

130 Broughton BR, Reutens DC, Sobey CG. Apoptotic mechanisms after cerebra ischemia. Stroke 2009:40:e331-9.

131 Park S, Yamaguchi M, Zhou C, et al. Neurovascular protection reduces early brain injury after subarachnoid hemorrhage. Stroke 2004;35:2412-17.

132 Friedrich V, Flores $\mathrm{R}$, Sehba FA. Cell death starts early after subarachnoid hemorrhage. Neurosci Lett 2012;512:6-11.

133 Graetz D, Nagel A, Schlenk F, et al. High ICP as trigger of proinflammatory IL-6 cytokine activation in aneurysmal subarachnoid hemorrhage. Neurol Res 2010;32:728-35

134 Yundt KD, Grubb RL Jr, Diringer MN, et al. Autoregulatory vasodilation of parenchymal vessels is impaired during cerebral vasospasm. J Cereb Blood Flow Metab 1998;18:419-24

135 Herz DA, Baez S, Shulman K. Pial microcirculation in subarachnoid hemorrhage. Stroke 1975:6:417-24.

136 Ohkuma H, Itoh K, Shibata S, et al. Morphological changes of intraparenchyma arterioles after experimental subarachnoid hemorrhage in dogs. Neurosurgery 1997:41:230-5; discussion 235-6.

137 Hart MN. Morphometry of brain parenchymal vessels following subarachnoid hemorrhage. Stroke 1980;11:653-5.

138 Frijns CJ, Fijnheer R, Algra A, et al. Early circulating levels of endothelial cell activation markers in aneurysmal subarachnoid haemorrhage: associations with cerebral ischaemic events and outcome. J Neurol Neurosurg Psychiatry 2006:77:77-83.

139 Ikeda K, Asakura H, Futami K, et al. Coagulative and fibrinolytic activation in cerebrospinal fluid and plasma after subarachnoid hemorrhage. Neurosurgery 1997:41:344-9; discussion 349-50.

140 Ohkuma H, Suzuki S, Kimura M, et al. Role of platelet function in symptomatic cerebral vasospasm following aneurysmal subarachnoid hemorrhage. Stroke 1991;22:854-9.

141 Peltonen $S$, Juvela $S$, Kaste $M$, et al. Hemostasis and fibrinolysis activation after subarachnoid hemorrhage. J Neurosurg 1997:87:207-14

142 Suzuki M, Kudo A, Otawara Y, et al. Extrinsic pathway of blood coagulation and thrombin in the cerebrospinal fluid after subarachnoid hemorrhage. Neurosurgery 1999:44:487-93; discussion 493-4.

143 Hirashima Y, Nakamura S, Endo S, et al. Elevation of platelet activating factor, inflammatory cytokines, and coagulation factors in the internal jugular vein of patients with subarachnoid hemorrhage. Neurochem Res 1997;22:1249-55.

144 Stein SC, Browne KD, Chen XH, et al. Thromboembolism and delayed cerebra ischemia after subarachnoid hemorrhage: an autopsy study. Neurosurgery 2006:59:781-7; discussion 787-8.

145 Roos Y. Antifibrinolytic treatment in subarachnoid hemorrhage: a randomized placebo-controlled trial. STAR Study Group. Neurology 2000;54:77-82.

146 Roos YB, Rinkel GJ, Vermeulen $M$, et al. Antifibrinolytic therapy for aneurysmal subarachnoid haemorrhage. Cochrane Database Syst Rev 2000;(2):CD001245.

147 Roos YB, Rinkel GJ, Vermeulen M, et al. Antifibrinolytic therapy for aneurysmal subarachnoid haemorrhage. Cochrane Database Syst Rev 2003;(2):CD001245.

148 Vermeulen M, Lindsay KW, Murray GD, et al. Antifibrinolytic treatment in subarachnoid hemorrhage. N Engl J Med 1984;311:432-7.

149 Tsementzis SA, Hitchcock ER, Meyer $\mathrm{CH}$. Benefits and risks of antifibrinolytic therapy in the management of ruptured intracranial aneurysms. A double-blind placebo-controlled study. Acta Neurochir (Wien) 1990:102:1-10.

150 Dorhout Mees SM, Rinkel GJ, Hop JW, et al. Antiplatelet therapy in aneurysmal subarachnoid hemorrhage: a systematic review. Stroke 2003;34:2285-9.

151 Dorhout Mees SM, van den Bergh WM, Algra A, et al. Antiplatelet therapy for aneurysmal subarachnoid haemorrhage. Cochrane Database Syst Rev 2007;(4): CD006184.

152 Chang JC, Shook LL, Biag J, et al. Biphasic direct current shift, haemoglobin desaturation and neurovascular uncoupling in cortical spreading depression. Brain 2011;133(Pt 4):996-1012

153 Takano T, Tian GF, Peng W, et al. Cortical spreading depression causes and coincides with tissue hypoxia. Nat Neurosci 2007;10:754-62.

154 Dreier JP, Major S, Manning A, et al. Cortical spreading ischaemia is a novel process involved in ischaemic damage in patients with aneurysmal subarachnoid haemorrhage. Brain 2009;132(Pt 7):1866-81.
155 Dreier JP, Woitzik J, Fabricius M, et al. Delayed ischaemic neurological deficits after subarachnoid haemorrhage are associated with clusters of spreading depolarizations. Brain 2006:129(Pt 12):3224-37.

156 Woitzik J, Dreier JP, Hecht N, et al. Delayed cerebral ischemia and spreading depolarization in absence of angiographic vasospasm after subarachnoid hemorrhage. J Cereb Blood Flow Metab 2012;32:203-12.

157 Bosche B, Graf R, Ernestus RI, et al. Recurrent spreading depolarizations after subarachnoid hemorrhage decreases oxygen availability in human cerebral cortex. Ann Neurol 2010;67:607-17.

158 Rasmussen G, Hauerberg J, Waldemar G, et al. Cerebral blood flow autoregulation in experimental subarachnoid haemorrhage in rat. Acta Neurochir (Wien) 1992;119:128-33.

159 Harper AM, Deshmukh VD, Sengupta D, et al. The effect of experimental spasm on the CO2 response of cerebral bloodflow in primates. Neuroradiology 1972;3:134-6

160 Harper AM, Glass HI. Effect of alterations in the arterial carbon dioxide tension on the blood flow through the cerebral cortex at normal and low arterial blood pressures. J Neurol Neurosurg Psychiatry 1965;28:449-52.

161 Fitch W, Ferguson GG, Sengupta D, et al. Autoregulation of cerebral blood flow during controlled hypotension in baboons. I Neurol Neurosurg Psychiatry 1976:39:1014-22.

162 Pickard JD, Matheson M, Patterson J, et al. Prediction of late ischemic complications after cerebral aneurysm surgery by the intraoperative measurement of cerebral blood flow. J Neurosurg 1980;53:305-8.

163 Budohoski KP, Czosnyka M, Smielewski P, et al. Impairment of cerebral autoregulation predicts delayed cerebral ischemia after subarachnoid hemorrhage: a prospective observational study. Stroke 2012;43:3230-7.

164 Budohoski KP, Czosnyka M, Smielewski P, et al. Cerebral autoregulation after subarachnoid hemorrhage: comparison of three methods. J Cereb Blood Flow Metab 2013:33:449-56.

165 Eide PK, Sorteberg A, Bentsen G, et al. Pressure-derived versus pressure wave amplitude-derived indices of cerebrovascular pressure reactivity in relation to early clinical state and 12-month outcome following aneurysmal subarachnoid hemorrhage. J Neurosurg 2012;116:961-71.

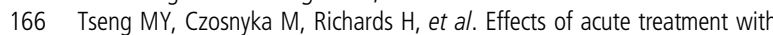
pravastatin on cerebral vasospasm, autoregulation, and delayed ischemic deficits after aneurysmal subarachnoid hemorrhage: a phase II randomized placebo-controlled trial. Stroke 2005;36:1627-32.

167 Tseng MY, Czosnyka M, Richards $\mathrm{H}$, et al. Effects of acute treatment with statins on cerebral autoregulation in patients after aneurysmal subarachnoid hemorrhage. Neurosurg Focus 2006:21:E10.

168 Tseng MY, Hutchinson PJ, Czosnyka M, et al. Effects of acute pravastatin treatment on intensity of rescue therapy, length of inpatient stay, and 6-month outcome in patients after aneurysmal subarachnoid hemorrhage. Stroke 2007:38:1545-50.

169 Sonobe M, Takahashi S, Otsuki T, et al. [Preventive effect on intracranial arterial vasospasm using combined ventriculo-cisternal and cisternal drainage (author's transl)]. No Shinkei Geka 1981;9:1393-7.

170 Al-Tamimi YZ, Bhargava D, Feltbower RG, et al. Lumbar drainage of cerebrospinal fluid after aneurysmal subarachnoid hemorrhage: a prospective, randomized, controlled trial (LUMAS). Stroke 2012;43:677-82.

171 Bardutzky J, Witsch J, Juttler $\mathrm{E}$, et al. EARLYDRAIN- outcome after early lumbar CSF-drainage in aneurysmal subarachnoid hemorrhage: study protocol for a randomized controlled trial. Trials 2011;12:203.

172 Findlay JM, Kassell NF, Weir BK, et al. A randomized trial of intraoperative, intracisternal tissue plasminogen activator for the prevention of vasospasm. Neurosurgery 1995;37:168-76; discussion 177-8.

173 Hamada J, Kai Y, Morioka M, et al. Effect on cerebral vasospasm of coil embolization followed by microcatheter intrathecal urokinase infusion into the cisterna magna: a prospective randomized study. Stroke 2003:34:2549-54

174 Hanggi D, Eicker S, Beseoglu K, et al. A multimodal concept in patients after severe aneurysmal subarachnoid hemorrhage: results of a controlled single centre prospective randomized multimodal phase I/II trial on cerebral vasospasm. Cent Eur Neurosurg 2009;70:61-7.

175 Kanamura K, Waga S, Sakakura M, et al. Comparative study of cisternal lavage methods for the treatment of cerebral vasospasm. Cerebral Vasospasm. Proceedings of the 5th international conference; 1993:471-73.

$176 \mathrm{Li}$ YH, Guo K, Zi XH, et al. [Combining exchange of cerebrospinal fluid with small dose of urokinase injection for subarachnoid hemorrhage]. Zhong Nan Da Xue Xue Bao Yi Xue Ban 2005:30:217-20.

177 Kramer $\mathrm{AH}$, Fletcher JJ. Locally-administered intrathecal thrombolytics following aneurysmal subarachnoid hemorrhage: a systematic review and meta-analysis. Neurocrit Care 2011:14:489-99.

178 Connolly ES Jr, Rabinstein AA, Carhuapoma JR, et al. Guidelines for the management of aneurysmal subarachnoid hemorrhage: a guideline for healthcare professionals from the American Heart Association/american Stroke Association. Stroke 2012:43:1711-37. 
179 Brandt L, Andersson KE, Edvinsson L, et al. Effects of extracellular calcium and of calcium antagonists on the contractile responses of isolated human pial and mesenteric arteries. J Cereb Blood Flow Metab 1981;1:339-47.

180 Roos YB, Levi M, Carroll TA, et al. Nimodipine increases fibrinolytic activity in patients with aneurysmal subarachnoid hemorrhage. Stroke 2001;32:1860-2.

181 Liu GJ, Wang ZJ, Wang YF, et al. Systematic assessment and meta-analysis of the efficacy and safety of fasudil in the treatment of cerebral vasospasm in patients with subarachnoid hemorrhage. Eur J Clin Pharmacol 2012;68:131-9.

182 Zhao J, Zhou D, Guo J, et al. Efficacy and safety of fasudil in patients with subarachnoid hemorrhage: final results of a randomized trial of fasudil versus nimodipine. Neurol Med Chir (Tokyo) 2011;51:679-83.

183 Birk S, Kruuse C, Petersen KA, et al. The phosphodiesterase 3 inhibitor cilostazol dilates large cerebral arteries in humans without affecting regional cerebral blood flow. J Cereb Blood Flow Metab 2004:24:1352-8.

184 Yamaguchi-Okada M, Nishizawa S, Mizutani A, et al. Multifaceted effects of selective inhibitor of phosphodiesterase III, cilostazol, for cerebral vasospasm after subarachnoid hemorrhage in a dog model. Cerebrovasc Dis 2009;28:135-42.

185 Suzuki S, Sayama T, Nakamura T, et al. Cilostazol improves outcome after subarachnoid hemorrhage: a preliminary report. Cerebrovasc Dis 2011;32:89-93.

186 Senbokuya N, Kinouchi H, Kanemaru K, et al. Effects of cilostazol on cerebral vasospasm after aneurysmal subarachnoid hemorrhage: a multicenter prospective, randomized, open-label blinded end point trial. J Neurosurg 2013;118:121-30.

187 Niu PP, Yang G, Xing YQ, et al. Effect of cilostazol in patients with aneurysmal subarachnoid hemorrhage: a systematic review and meta-analysis. J Neurol Sci 2014:336:146-51.

188 Kasuya H, Onda H, Sasahara A, et al. Application of nicardipine prolonged-release implants: analysis of 97 consecutive patients with acute subarachnoid hemorrhage. Neurosurgery 2005;56:895-902; discussion 895-902.

189 Barth M, Capelle HH, Weidauer S, et al. Effect of nicardipine prolonged-release implants on cerebral vasospasm and clinical outcome after severe aneurysmal subarachnoid hemorrhage: a prospective, randomized, double-blind phase lla study. Stroke 2007;38:330-6.

190 Zwienenberg-Lee M, Hartman J, Rudisill N, et al. Effect of prophylactic transluminal balloon angioplasty on cerebral vasospasm and outcome in patients with Fisher grade III subarachnoid hemorrhage: results of a phase II multicenter, randomized, clinical trial. Stroke 2008:39:1759-65.

191 Chou SH, Smith EE, Badjatia N, et al. A randomized, double-blind, placebo-controlled pilot study of simvastatin in aneurysmal subarachnoid hemorrhage. Stroke 2008;39:2891-3.

192 Lynch JR, Wang H, McGirt MJ, et al. Simvastatin reduces vasospasm after aneurysmal subarachnoid hemorrhage: results of a pilot randomized clinical trial. Stroke 2005;36:2024-6.

193 Vergouwen MD, Meijers JC, Geskus RB, et al. Biologic effects of simvastatin in patients with aneurysmal subarachnoid hemorrhage: a double-blind, placebo-controlled randomized trial. J Cereb Blood Flow Metab 2009:29:1444-53.

194 McLean RM. Magnesium and its therapeutic uses: a review. Am J Med 1994:96:63-76

195 van den Bergh WM, Algra A, van der Sprenkel JW, et al. Hypomagnesemia after aneurysmal subarachnoid hemorrhage. Neurosurgery 2003;52:276-81; discussion 281-2.

196 Dorhout Mees SM, Algra A, Vandertop WP, et al. Magnesium for aneurysmal subarachnoid haemorrhage (MASH-2): a randomised placebo-controlled trial. Lancet 2012;380:44-9.

197 Digicaylioglu M, Lipton SA. Erythropoietin-mediated neuroprotection involves cross-talk between Jak2 and NF-kappaB signalling cascades. Nature 2001:412:641-7.
198 Springborg JB, Ma X, Rochat $\mathrm{P}$, et al. A single subcutaneous bolus of erythropoietin normalizes cerebral blood flow autoregulation after subarachnoid haemorrhage in rats. Br J Pharmacol 2002:135:823-9.

199 Grasso G, Buemi M, Alafaci C, et al. Beneficial effects of systemic administration of recombinant human erythropoietin in rabbits subjected to subarachnoid hemorrhage. Proc Natl Acad Sci U S A 2002;99:5627-31.

200 Tseng MY, Hutchinson PJ, Richards HK, et al. Acute systemic erythropoietin therapy to reduce delayed ischemic deficits following aneurysmal subarachnoid hemorrhage: a Phase II randomized, double-blind, placebo-controlled trial. Clinical article. J Neurosurg 2009;111:171-80.

201 Suarez JI, Shannon L, Zaidat 00, et al. Effect of human albumin administration on clinical outcome and hospital cost in patients with subarachnoid hemorrhage. J Neurosurg 2004;100:585-90.

202 Siironen J, Juvela S, Varis J, et al. No effect of enoxaparin on outcome of aneurysmal subarachnoid hemorrhage: a randomized, double-blind, placebo-controlled clinical trial. J Neurosurg 2003:99:953-9.

203 Wurm G, Tomancok B, Nussbaumer K, et al. Reduction of ischemic sequelae following spontaneous subarachnoid hemorrhage: a double-blind, randomized comparison of enoxaparin versus placebo. Clin Neurol Neurosurg 2004;106:97-103

204 Haley EC Jr, Kassell NF, Apperson-Hansen C, et al. A randomized, double-blind, vehicle-controlled trial of tirilazad mesylate in patients with aneurysmal subarachnoid hemorrhage: a cooperative study in North America. J Neurosurg 1997;86:467-74.

205 Kassell NF, Haley EC Jr, Apperson-Hansen C, et al. Randomized, double-blind, vehicle-controlled trial of tirilazad mesylate in patients with aneurysmal subarachnoid hemorrhage: a cooperative study in Europe, Australia, and New Zealand. J Neurosurg 1996;84:221-8.

206 Lanzino G, Kassell NF. Double-blind, randomized, vehicle-controlled study of high-dose tirilazad mesylate in women with aneurysmal subarachnoid hemorrhage. Part II. A cooperative study in North America. J Neurosurg 1999;90:1018-24.

207 Lanzino G, Kassell NF, Dorsch NW, et al. Double-blind, randomized, vehicle-controlled study of high-dose tirilazad mesylate in women with aneurysmal subarachnoid hemorrhage. Part I. A cooperative study in Europe, Australia, New Zealand, and South Africa. J Neurosurg 1999;90:1011-17.

208 Jang YG, llodigwe D, Macdonald RL. Metaanalysis of tirilazad mesylate in patients with aneurysmal subarachnoid hemorrhage. Neurocrit Care 2009;10:141-7.

209 Zhang S, Wang L, Liu M, et al. Tirilazad for aneurysmal subarachnoid haemorrhage. Cochrane Database Syst Rev 2010;(2):CD006778.

210 Asano T, Takakura K, Sano K, et al. Effects of a hydroxyl radical scavenger on delayed ischemic neurological deficits following aneurysmal subarachnoid hemorrhage: results of a multicenter, placebo-controlled double-blind trial. J Neurosurg 1996;84:792-803.

211 Saito I, Asano T, Sano K, et al. Neuroprotective effect of an antioxidant, ebselen, in patients with delayed neurological deficits after aneurysmal subarachnoid hemorrhage. Neurosurgery 1998;42:269-77; discussion 277-8.

212 Munakata A, Ohkuma $\mathrm{H}$, Nakano $\mathrm{T}$, et al. Effect of a free radical scavenger, edaravone, in the treatment of patients with aneurysmal subarachnoid hemorrhage. Neurosurgery 2009:64:423-8; discussion 428-9.

213 Suzuki S, Sano K, Handa H, et al. Clinical study of OKY-046, a thromboxane synthetase inhibitor, in prevention of cerebral vasospasms and delayed cerebral ischaemic symptoms after subarachnoid haemorrhage due to aneurysmal rupture: a randomized double-blind study. Neurol Res 1989;11:79-88.

214 Gomis P, Graftieaux JP, Sercombe R, et al. Randomized, double-blind, placebo-controlled, pilot trial of high-dose methylprednisolone in aneurysmal subarachnoid hemorrhage. J Neurosurg 2010;112:681-8. 